02

\title{
Спектрально-люминесцентные свойства разнолигандных комплексных соединений европия(III) с n-метилбензойной кислотой
}

\author{
(C) И.В. Калиновская, А.Н. Задорожная \\ ${ }^{1}$ Институт химии Дальневосточного отделения РАН, \\ 690022 Владивосток, Россия \\ 2 Тихоокеанский государственный медицинский университет, \\ 690002 Владивосток, Россия \\ e-mail: kalinovskaya@ich.dvo.ru
}

Поступила в редакцию 27.02.2019 г.

В окончательной редакции 15.04.2019 г.

Принята к публикации 04.06.2019 г.

Изучены спектрально-люминесцентные свойства комплексных соединений европия(III) с $n$-метилбензойной кислотой, азот- и фосфорсодержащими нейтральными лигандами состава $\left[\mathrm{Eu}(\mathrm{p}-\mathrm{MBA})_{3} \cdot \mathrm{D}\right]_{2} \cdot x \mathrm{H}_{2} \mathrm{O}$ и $\left[\mathrm{Eu}(\mathrm{p}-\mathrm{MBA})_{3} \cdot 2 \mathrm{H}_{2} \mathrm{O}\right]_{n}$, где $\mathrm{p}-\mathrm{MBA}$ анион $n$-метилбензойной кислоты, D - 1,10-фенантролин (phen), 2,2'-дипиридил (dipy), трифенилфосфиноксид (tppo) (=0), гексаметилфосфотриамид (hmpa) $(x=1)$, бензтриазол $(\mathrm{bt})(x=2)$. Проведен анализ электронных спектров поглощения, спектров возбуждения люминесценции и штарковской структуры электронных переходов ${ }^{5} D_{0}-{ }^{7} F_{j}(j=0-2)$ в низкотемпературных спектрах люминесценции комплексных $n$-метилбензоатов европия(III). Установлено, что передача энергии возбуждения к иону европия осуществляется как с уровней $n$-метилбензойной кислоты, так и с уровней нейтральных лигандов.

Ключевые слова: люминесценция, комплексные соединения, $n$-метилбензойная кислота, европий.

DOI: $10.21883 /$ OS.2019.11.48512.71-19

Разработка интенсивных люминесцентных и фотостабильных функциональных материалов на основе редкоземельных комплексных соединений для оптоэлектроники, аналитической химии, сельского хозяйства и медицины является актуальной задачей [1-4]. Изучение фотофизических свойств координационных соединений лантаноидов необходимо для целенаправленного синтеза новых люминесцирующих соединений редкоземельных элементов. Интенсивные люминесцентные, триболюминесцентные, сенсорные и фотохимические свойства комплексов лантаноидов позволяют использовать их в качестве легирующих примесей для функциональных оптических материалов (светопреобразующих материалов).

Одним из перспективных классов люминесцирующих фотоустойчивых комплексных соединений редкоземельных элементов являются комплексные соединения с карбоксилсодержащими лигандами типа кислот [5-7]. Органические карбоновые кислоты используют как распространенные мостиковые лиганды в комплексных соединениях $f$-элементов и подобно другим мостиковым лигандам в целом определяют физико-химические свойства данных комплексных соединений. Большое разнообразие состава и строения карбоксилатов лантаноидов, многообразие их физико-химических свойств позволяют считать комплексы с карбоновыми кислотами удобными модельными обьектами для изучения связи между физико-химическими свойствами и строением соединений. Данные комплексные соединения лантаноидов с карбоновыми кислотами успешно используются для получения функциональных оптических материалов для нужд оптоэлектроники, сенсорики, медицины [8-15].

Метилбензойные кислоты - мостиковые лиганды в комплексных соединениях - во многом определяют физико-химические свойства этих соединений [16-20]. Сведения о синтезе и физико-химических свойствах разнолигандных соединений редкоземельных элементов (РЗЭ) с $n$-метилбензойной кислотой ограничены $[18,19]$. Описанные в литературе разнолигандные комплексные соединения РЗЭ являются димерами, в которых реализуется как бидентатная, так и мостиковая координации кислотных остатков $[16,18,19]$. В то время как гидрат толуилата европия(III) представлен бесконечной полимерной цепочкой состава $\left[\mathrm{Eu}(\mathrm{MBA})_{3} \cdot 2 \mathrm{H}_{2} \mathrm{O}\right]_{n}[20]$.

В настоящей работе представлены результаты изучения спектрально-люминесцентных свойств комплексных соединений европия(III) с $n$-метилбензойной кислотой азот- и фосфорсодержащими нейтральными лигандами состава $\left[\mathrm{Eu}(\mathrm{p}-\mathrm{MBA})_{3} \cdot \mathrm{D}\right]_{2} \cdot x \mathrm{H}_{2} \mathrm{O}$ и $[\mathrm{Eu}(\mathrm{p}-$ $\left.\mathrm{MBA})_{3} \cdot 2 \mathrm{H}_{2} \mathrm{O}\right]_{n}$, где $\mathrm{p}-\mathrm{MBA}$ - анион $n$-метилбензойной кислоты, D - 1,10-фенантролин (phen), 2,2'-дипиридил (dipy), трифенилфосфиноксид (tppo), диметилформамид $(\mathrm{dmf})(x=0)$, гексаметилфосфотриамид (hmpa) $(x=1)$, бензтриазол (bt) $(x=2)$.

\section{Экспериментальная часть}

Для синтеза разнолигандных комплексных соединений европия $(\mathrm{III})$ состава $\left[\mathrm{Eu}(\mathrm{p}-\mathrm{MBA})_{3} \cdot \mathrm{D}\right]_{2} \cdot x \mathrm{H}_{2} \mathrm{O}$ и 




Рис. 1. Электронные спектры поглощения $10^{-4} \mathrm{M}$-растворов $\left(\mathrm{C}_{2} \mathrm{H}_{5} \mathrm{OH}\right): 1-\mathrm{p}-\mathrm{HMBA}, 2-\left[\mathrm{Eu}(\mathrm{p}-\mathrm{MBA})_{3} \cdot 2 \mathrm{H}_{2} \mathrm{O}\right]_{n}$, $3-\left[\mathrm{Eu}(\mathrm{p}-\mathrm{MBA})_{3} \cdot \mathrm{tppo}\right]_{2}, 4-\left[\mathrm{Eu}(\mathrm{p}-\mathrm{MBA})_{3} \cdot \operatorname{dipy}\right]_{2}, 5-$ $\left[\mathrm{Eu}(\mathrm{p}-\mathrm{MBA})_{3} \cdot \mathrm{bt}\right]_{2} \cdot 2 \mathrm{H}_{2} \mathrm{O}$.

$\left[\mathrm{Eu}(\mathrm{p}-\mathrm{MBA})_{3} \cdot 2 \mathrm{H}_{2} \mathrm{O}\right]_{n}$ использовали следующие препараты марки „ч“: шестиводный нитрат европия(III), nметилбензойную кислоту, азотсодержащие нейтральные лиганды (dipy, phen, bt, dmf) и фосфорсодержащие нейтральные лиганды (tppo, hmpa).

Синтез разнолигандных соединений осуществляли по следующей методике: к $3 \mathrm{mM} \mathrm{NaOH}$, растворенного в минимальном количестве воды, добавляли $3 \mathrm{mM} n$ метилбензойной кислоты. Затем к смеси добавляли $1 \mathrm{mM} \mathrm{Eu}\left(\mathrm{NO}_{3}\right)_{3} \cdot 6 \mathrm{H}_{2} \mathrm{O}$, растворенного в $10-15 \mathrm{ml} \mathrm{H}_{2} \mathrm{O}$ и $2 \mathrm{mM}$ нейтрального лиганда в $15-20 \mathrm{ml} \mathrm{96 \% -этило-}$ вого спирта. $\mathrm{pH}$ реакционной смеси доводили до 6-7 10\%-раствором аммиака и оставляли стоять до образования осадка. Осадок отфильтровывали, промывали водой и сушили на воздухе. Выход составил 75-83\%.

Низкотемпературные спектры люминесценции регистрировали на спектрометре СДЛ-1. Возбуждение осуществляли ртутной лампой ДРШ-250. Ошибка измерений волновых чисел полос переходов ${ }^{5} D_{0}-{ }^{7} F_{j}(j=0-4)$ не превышает $\pm 2-3 \mathrm{~cm}^{-1}$ (число определений не меньше 5). Шкала длин волн спектрометра СДЛ-1 выверялась по линиям гелий-неонового источника и дублета ртути 576 и $579 \mathrm{~nm}$.

Спектры возбуждения люминесценции регистрировали на приборе RF-5301 Shimadzu.

Электронные спектры поглощения - на спектрометpe RF-2550 Shimadzu. Концентрация соединения в 96\%этаноле равна $10^{-4} \mathrm{M} / 1$.

\section{Результаты и их обсуждение}

Электронные спектры поглощения полученных соединений европия с $n$-метилбензойной кислотой, азот- и фосфорсодержащими нейтральными лигадами приведены на рис. 1. Как видно из рис. 1, комплексообразование приводит к изменению положения полосы, соответствующей переходу $\pi-\pi^{*} n$-метилбензойной кислоты $\left(\lambda_{\max }=225-235 \mathrm{~nm}\right)$. Для полученных разнолигандных метилбензоатов европия(III) характерен более сложный вид спектров поглощения, чем для $n$-метилбензойной кислоты. В электронных спектрах поглощения $(Э С П)\left[\mathrm{Eu}(\mathrm{p}-\mathrm{MBA})_{3} \cdot \mathrm{bta}\right]_{2} \cdot 2 \mathrm{H}_{2} \mathrm{O},\left[\mathrm{Eu}(\mathrm{p}-\mathrm{MBA})_{3} \cdot \mathrm{tppo}_{2}\right.$ и $\left[\mathrm{Eu}(\mathrm{p}-\mathrm{MBA})_{3} \cdot \operatorname{dipy}\right]_{2}$ наблюдаются дополнительные полосы поглощения, характерные для координированных нейтральных молекул лигандов. Так, в спектре $[\mathrm{Eu}(\mathrm{p}$ $\left.\mathrm{MBA})_{3} \cdot \operatorname{dipy}\right]_{2}$ проявляется полоса поглощения dipy c $\lambda_{\max }=260-300 \mathrm{~nm}$. В ЭСП $\left[\mathrm{Eu}(\mathrm{p}-\mathrm{MBA})_{3} \cdot \mathrm{tppo}\right]_{2}$ полоса поглощения p-MBA с $\lambda_{\max }=215-250 \mathrm{~nm}$ сдвинута в более коротковолновую область по сравнению c ее положением в спектре „свободной“ $n$-метилбензойной кислоты, которая обязана синглетному $\left(S \pi \pi^{*}\right)$ переходу [8].

Полученные нами разнолигандные $n$-метилбензоаты европия(III) люминесцируют (в твердом состоянии) как при комнатной температуре, так и при $77 \mathrm{~K}$ (рис. 2). Общий характер спектров люминесценции по ряду полученных $n$-метилбензоатов европия(III) с азот- и фосфорсодержащими нейтральными лигандами сохраняется. В спектрах люминесценции комплексных соединений

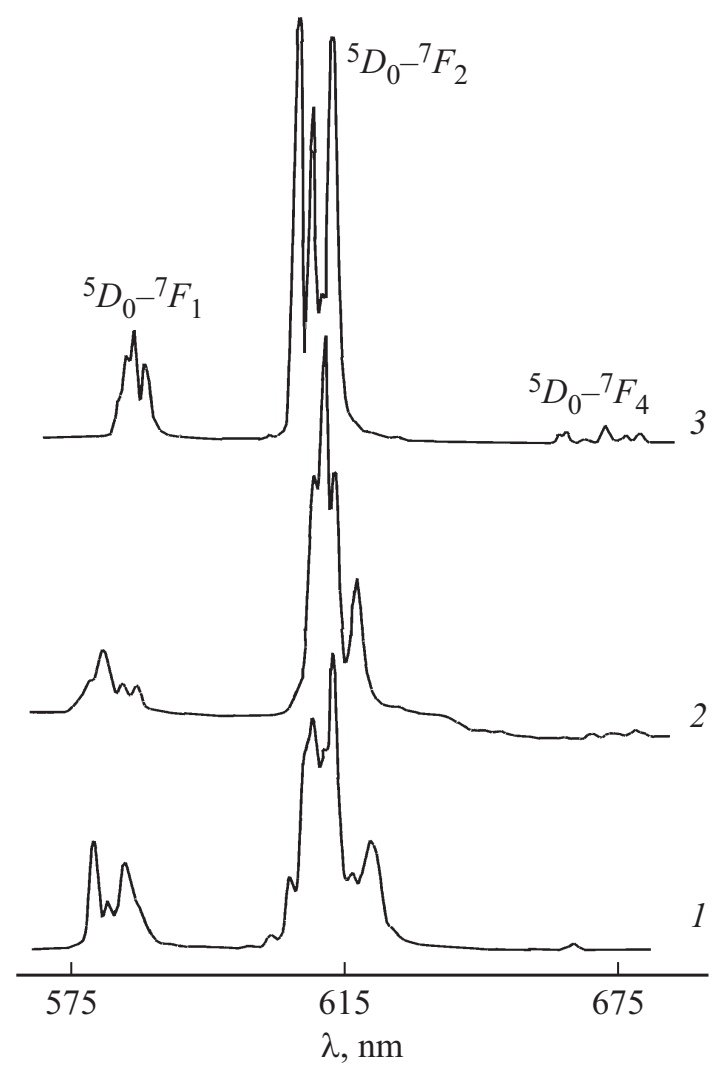

Рис. 2. Спектры люминесценции при $293 \mathrm{~K}: 1$ $\left[\mathrm{Eu}(\mathrm{p}-\mathrm{MBA})_{3} \cdot 2 \mathrm{H}_{2} \mathrm{O}\right]_{n}, \quad 2-\left[\mathrm{Eu}(\mathrm{p}-\mathrm{MBA})_{3} \cdot \text { phen }\right]_{2}, \quad 3-$ $\left[\mathrm{Eu}(\mathrm{p}-\mathrm{MBA})_{3} \cdot \mathrm{dipy}\right]_{2}$. 
Значение интенсивности люминесценции разнолигандных метилбензоатов европия при $293 \mathrm{~K}$

\begin{tabular}{c|c}
\hline Соединение & $I_{\text {отн }}$ \\
\hline$\left[\mathrm{Eu}(\mathrm{p}-\mathrm{MBA})_{3} \cdot 2 \mathrm{H}_{2} \mathrm{O}\right]_{n}$ & 1.0 \\
{$\left[\mathrm{Eu}(\mathrm{p}-\mathrm{MBA})_{3} \cdot \mathrm{tppo}\right]_{2}$} & 1.5 \\
{$\left[\mathrm{Eu}(\mathrm{p}-\mathrm{MBA})_{3} \cdot \mathrm{bt}\right]_{2} \cdot 2 \mathrm{H}_{2} \mathrm{O}$} & 1.2 \\
{$\left[\mathrm{Eu}(\mathrm{p}-\mathrm{MBA})_{3} \cdot \mathrm{dipy}\right]_{2}$} & 5.0 \\
{$\left[\mathrm{Eu}(\mathrm{p}-\mathrm{MBA})_{3} \cdot \mathrm{phen}\right]_{2}$} & 5.7 \\
{$\left[\mathrm{Eu}(\mathrm{p}-\mathrm{MBA})_{3} \cdot \mathrm{dmf}\right]_{2}$} & 1.3 \\
{$\left[\mathrm{Eu}(\mathrm{p}-\mathrm{MBA})_{3} \cdot \mathrm{hmpa}\right]_{2} \cdot \mathrm{H}_{2} \mathrm{O}$} & 1.3 \\
{$\left[\mathrm{Eu}(\mathrm{M}-\mathrm{MBA})_{3} \cdot 2 \mathrm{H}_{2} \mathrm{O}\right]_{n}$} & 5.7 \\
{$\left[\mathrm{Eu}(\mathrm{p}-\mathrm{MBA})_{3} \cdot \mathrm{tppo}\right]_{2} \cdot 2 \mathrm{H}_{2} \mathrm{O}$} & 8.6 \\
{$\left[\mathrm{Eu}(\mathrm{p}-\mathrm{MBA})_{3} \cdot \mathrm{bt}\right]_{2} \cdot 2 \mathrm{H}_{2} \mathrm{O}$} & 6.8 \\
{$\left[\mathrm{Eu}(\mathrm{p}-\mathrm{MBA})_{3} \cdot \mathrm{dipy}\right]_{2}$} & 20 \\
{$\left[\mathrm{Eu}(\mathrm{p}-\mathrm{MBA})_{3} \cdot \mathrm{phem}\right]_{2}$} & 17 \\
{$\left[\mathrm{Eu}(\mathrm{p}-\mathrm{MBA})_{3} \cdot \mathrm{dmf}\right]_{2} \cdot 2 \mathrm{H}_{2} \mathrm{O}$} & 7.4 \\
{$\left[\mathrm{Eu}(\mathrm{p}-\mathrm{MBA})_{3} \cdot \mathrm{hmpa}\right]_{2} \cdot 2 \mathrm{H}_{2} \mathrm{O}$} & 7.4
\end{tabular}

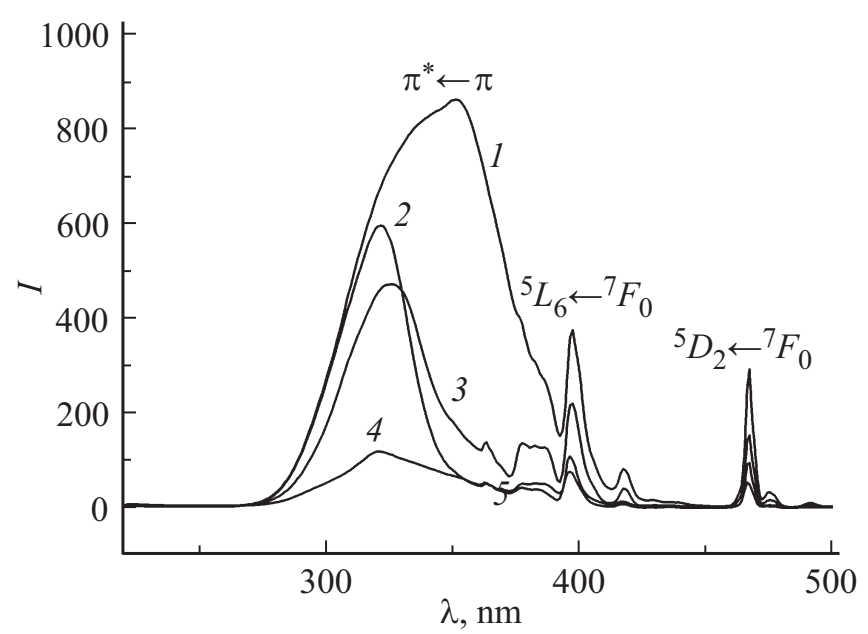

Рис. 3. Спектры возбуждения люминесценции при $293 \mathrm{~K}, \quad \lambda_{\text {per }}=612 \mathrm{~nm}: \quad 1-\left[\mathrm{Eu}(\mathrm{p}-\mathrm{MBA})_{3} \cdot \mathrm{phen}\right]_{2}, \quad 2-$ $\left[\mathrm{Eu}(\mathrm{M}-\mathrm{MBA})_{3} \cdot 2 \mathrm{H}_{2} \mathrm{O}\right]_{n}, \quad 3-\left[\mathrm{Eu}(\mathrm{p}-\mathrm{MBA})_{3} \cdot \mathrm{dipy}\right]_{2}, \quad 4-$ $\left[\mathrm{Eu}(\mathrm{p}-\mathrm{MBA})_{3} \cdot 2 \mathrm{H}_{2} \mathrm{O}\right]_{n}$.

наиболее интенсивные полосы относятся к электродипольному переходу ${ }^{5} D_{0}-{ }^{7} F_{2}$. Данный переход является наиболее чувствительным к замене нейтрального лиганда в разнолигандных комплексах: наблюдается перераспределение интенсивностей отдельных линий и изменения в структуре расщепления штарковских компонент уровня ${ }^{7} F_{2}$. В спектрах люминесценции комплексных соединений в области электродипольного перехода ${ }^{5} D_{0}-{ }^{7} F_{2}$ наблюдаются до 5 компонент. Интенсивность полос магнитодипольного перехода ${ }^{5} D_{0}-{ }^{7} F_{1}$ на порядок ниже интенсивности полос электродипольного перехода ${ }^{5} D_{0}-{ }^{7} F_{2}$. Расщепление двух крайних полос магнитодипольного перехода ${ }^{5} D_{0}-{ }^{7} F_{1}$ существенно меняется при замене нейтрального лиганда, что указывает на вхождение его в координационную сферу иона европия(III).
Для полученных нами разнолигандных комплексных соединений европия(III) были определены значения интегральных интенсивностей перехода ${ }^{5} D_{0}-{ }^{7} F_{2}$ иона европия(III) (таблица). Было обнаружено увеличение интенсивности люминесценции перехода европия при переходе от гидратов к комплексным соединениям с нейтральными лигандами. Для $n$-метилбензоатов европия с 1,10-фенантролином и 2,2'-дипиридилом характерно максимальное значение интенсивности люминесценции, обусловленное наличием более развитой $\pi$-сопряженной системы эффективных поглотителей УФ света и отсутствием молекул воды в координационной сфере комплекса.

Нами проведено сопоставление интенсивности люминесценции $m$-метилбензоатов и $n$-метилбензоатов. Было установлено, что при введении в пара-положение по отношению к фенильному кольцу метильного заместителя в отличие от мета-положения интенсивность люминесценции комплексных соединений европия(III) существенно уменьшается. Так, сравнительный анализ интенсивности люминесценции разнолигандных комплексных $n$-метилбензоатов европия(III) и изученных раннее $m$ метилбензоатов [21] указывает на то, что интенсивность люминесценции $m$-метилбензоатов европия(III) существенно выше (в 2-5 раз) n-метилбензоатов. Это, повидимому, можно объяснить более электронодонорными свойствами $m$-метилбензойной кислоты (метильная группа ближе расположена к карбоксильной группе кислоты).

Спектры возбуждения люминесценции разнолигандых соединений европия(III) с $n$-метилбензойной кислотой состоят из широкой высокочастотной полосы, обусловленной полосами поглощения лигандов и узких линий переходов $f-f$ ионов $\mathrm{Eu}^{3+}$. В спектрах возбуждения разнолигандных соединений европия присутствуют полосы переходов $\pi \pi^{*}$ и $n \pi^{*} n$-метилбензойной кислоты и соответствующего азот- или фосфорсодержащего нейтрального лиганда (рис. 3), что приводит к эффективной передаче энергии как с триплетных уровней кислоты, так и с уровней нейтрального лиганда на европий. Как видно из спектров возбуждения люминесценции, интенсивность переходов $\pi \pi^{*}$ и $n \pi^{*} m$-метилбензойной кислоты в $\left[\mathrm{Eu}(\mathrm{M}-\mathrm{MBA})_{3} \cdot 2 \mathrm{H}_{2} \mathrm{O}\right]_{n}$ гораздо выше, чем интенсивность полос этих же переходов $n$-метилбензойной кислоты в $\left[\mathrm{Eu}(\mathrm{p}-\mathrm{MBA})_{3} \cdot 2 \mathrm{H}_{2} \mathrm{O}\right]_{n}$.

Таким образом, нами синтезированы новые люминесцирующие разнолигандные комплексные $n$-метилбензоаты европия(III) с азот- и фосфорсодержащими нейтральными лигандами. Показано, что передача энергии возбуждения к иону европия осуществляется как с уровней $n$-метилбензойной кислоты, так и с уровней нейтральных лигандов. Сравнительный анализ интенсивности люминесценции разнолигандных комплексных napaметилбензоатов европия(III) и изученных раннее метаметилбензоатов указывает на то, что интенсивность люминесценции мета-метилбензоатов европия(III) выше люминесценции $n$-метилбензоатов. 


\section{Финансирование работы}

Работа выполнена при финансовой поддержке Минобрнауки, номер темы государственного задания 02652014-0001.

\section{Конфликт интересов}

Авторы заявляют, что у них нет конфликта интересов.

\section{Список литературы}

[1] Zhao L., Chen Y., Chai X., Cui G., Ren L., Yang Y., Zhang H., Deng X. // J. Molecular Structaure. 2013. V. 1032. P. 213.

[2] Li Y., Yan B. // J. Solid State Chemistry.2008. V. 181. P. 1032.

[3] Zhao L., Chen Y., Zhang H., Li C., Sun R., Yang Q. // J. Molecular Structure. 2009. V. 920. P. 441.

[4] Chen Z.M., Wang S.P., Yang N., Zhao N., Zhang J.J., Wang R.F., Zhao B.H. // Rus. J. Coord. Chem. 2009. V. 35. P. 541.

[5] Bunzli J.-C.G., Eliseeva S.V. // Chem. Sci. 2013. V. 4. N 5. P. 1913.

[6] Zhang J., Wang R., Bai J., Wang S. // J. Rare Earths. 2002. V. 20. P. 449.

[7] Hasegawa Y., Nakanishi T. // RSC. Adv. 2015. V. 5. P. 338.

[8] Калиновская И.В., Карасев В.Е., Пяткина А.Н. // Журн. неорг. химии. 1999. Т. 44. № 3. С. 432.

[9] Kalinovskaya I.V. // J. Mol. Struct. 2018. V. 1173. P. 328-331. doi $10.1016 /$ j. molstruc. 2018.06.118

[10] Kurbatov I.A., Kharchenko V.I., Mirochnik A.G., Petrochenkova N.V., Zhikhareva P.A., Vovna V.I. // J. Structural Chemistry. 2018. V. 59. N 2. P. 328-334. doi $10.1134 / \mathrm{S} 0022476618020105$

[11] Калиновская И.В., Николенко Ю.М. // Опт. и спектр. 2018. T. 125. № 3. C. 344-347. doi 10.1134/S0030400X18090126

[12] Kataoka H., Kitano T., Takizawa T., Hirai Y., Nakanishi T., Hasegawa Y. // J. Alloys Compd. 2014. V. 601. P. 293.

[13] Lam A.W.H., Wong W.T., Gao S., Wen G.H., Zhang X.X. // Eur. J. Inorg. Chem. 2003. № 1. P. 149-163.

[14] Hui-Juan Sun, Ai-Ling Wang, Hai-Bin Chu, YoungLiang Zhao // Luminescence. 2015. V. 30. P. 131-136.

[15] Блатун Л.А., Митиш В.А., Терехова Р.П. и др. // Журнал им. проф. Б.М. Костюченка. 2014. Т. І. С. 13-21.

[16] Jin L.-P., Wang R.-F., Wang M.-Z. // Chem. J. Chin. Univ. 1993. V. 14. N 9. P. 1195.

[17] Yang Q.Q., Zhu Z.J. // Rare Metals. 2000. V. 19. N 1. P. 59.

[18] Zhang J., Wang R., Bai J., Wang S. // J. Rare Earths. 2002. V. 20. N 5. P. 449.

[19] Wang Rui-Fen, Jin Lin-Pei, Wang Ming-Zhao, Huang ShiHua, Chen Xue-Tai. // Acta Chim. Sin. 1995. V. 53. P. 39.

[20] Lam A.W.H., Wong W.T., Gao S., Wen G.H., Zhang X.X. // Eur. J. Inorg. Chem. 2003. V. 1. P. 149.

[21] Задорожная А.Н., Калиновская И.В., Карасев В.Е., Шапкин Н.П. // Коорд. химия. 2001. Т. 27. № 7. С. 555. 